Article

\title{
An Alcohol Dehydrogenase 3 (ADH3) from Entamoeba histolytica Is Involved in the Detoxification of Toxic Aldehydes
}

\author{
Constantin König ${ }^{1, \dagger}$, Martin Meyer ${ }^{1, \dagger}$, Corinna Lender ${ }^{1}$, Sarah Nehls ${ }^{1}$, Tina Wallaschkowski ${ }^{1}$, \\ Tobias Holm ${ }^{1}$, Thorben Matthies ${ }^{1}$, Dirk Lercher ${ }^{1}$, Jenny Matthiesen ${ }^{1}$, Helena Fehling ${ }^{1}{ }^{\mathbb{D}}$, \\ Thomas Roeder ${ }^{2}$, Sophia Reindl ${ }^{1}$, Maria Rosenthal ${ }^{1}{ }^{\mathbb{D}}$, Nahla Galal Metwally ${ }^{1} \mathbb{D}$, \\ Hannelore Lotter ${ }^{1}$ and Iris Bruchhaus ${ }^{1, *(D)}$ \\ 1 Bernhard Nocht Institute for Tropical Medicine, 20359 Hamburg, Germany; \\ constantin.koenig@bnitm.de (C.K.); martin_meyer2003@yahoo.de (M.M.); corinna.lender@gmx.de (C.L.); \\ sarah_nehls@web.de (S.N.); tina.wallaschkowski@googlemail.com (T.W.); tobiasholm@gmx.de (T.H.); \\ thorben.matthies89@gmail.com (T.M.); lercher-koeln@gmx.de (D.L.); jenny.m@gmx.com (J.M.); \\ fehling@bnitm.de (H.F.); sophia.reindl@googlemail.com (S.R.); rosenthal@bnitm.de (M.R.); \\ metwally@bnitm.de (N.G.M.); lotter@bnitm.de (H.L.) \\ 2 Molecular Physiology Department, Zoological Institute, Christian-Albrechts University Kiel, \\ 24118 Kiel, Germany; throeder1@googlemail.com \\ * Correspondence: bruchhaus@bnitm.de \\ + These authors contributed equally to this work.
}

Received: 4 September 2020; Accepted: 16 October 2020; Published: 19 October 2020

\begin{abstract}
Recently, a putative alcohol dehydrogenase 3, termed EhADH3B of the Entamoeba histolytica isolate HM-1:IMSS was identified, which is expressed at higher levels in non-pathogenic than in pathogenic amoebae and whose overexpression reduces the virulence of pathogenic amoebae. In an in silico analysis performed in this study, we assigned EhADH3B to a four-member ADH3 family, with ehadh $3 b$ present as a duplicate $\left(e h a d h 3 b^{a} / e h a d h 3 b^{b}\right)$. In long-term laboratory cultures a mutation was identified at position 496 of ehadh $3 b^{a}$, which codes for a stop codon, which was not the case for amoebae isolated from human stool samples. When using transfectants that overexpress or silence ehadh $3 b^{b}$, we found no or little effect on growth, size, erythrophagocytosis, motility, hemolytic or cysteine peptidase activity. Biochemical characterization of the recombinant EhADH3B ${ }^{\mathrm{b}}$ revealed that this protein forms a dimer containing $\mathrm{Ni}^{2+}$ or $\mathrm{Zn}^{2+}$ as a co-factor and that the enzyme converts acetaldehyde and formaldehyde in the presence of NADPH. A catalytic activity based on alcohols as substrates was not detected. Based on the results, we postulate that EhADH3B ${ }^{\mathrm{b}}$ can reduce free acetaldehyde released by hydrolysis from bifunctional acetaldehyde/alcohol dehydrogenase-bound thiohemiacetal and that it is involved in detoxification of toxic aldehydes produced by the host or the gut microbiota.
\end{abstract}

Keywords: Entamoeba histolytica; aldehyde reductase; acetaldehyde; formaldehyde; alcohol dehydrogenase

\section{Introduction}

The intestinal protozoan Entamoeba histolytica is an important human parasite. Recent data clearly indicate that the life-threating amoebic liver abscess (ALA) continues to be a common clinical complication of amoebiasis infection in Asian, African, and Latin American countries with 11.300 death in 2013 [1]. The life cycle of this parasite consists of infectious cysts that survive outside the host and vegetative trophozoites that proliferate in the human gut. In general, trophozoites persist asymptomatically for 
months or years in the human intestine. However, in 10\% of the cases, the trophozoites become invasive and induce extraintestinal amoebiasis (amoebic colitis, ALA).

Entamoeba histolytica is an anaerobic organism that converts pyruvate to ethanol by glucose fermentation [2]. Under anaerobic conditions, the main end products are ethanol and $\mathrm{CO}_{2}$. The amoebae form ethanol from acetyl-CoA as they do not have pyruvate decarboxylases. Under anaerobic conditions, reducing equivalents $\left(\mathrm{NAD}(\mathrm{P})^{+}\right)$are produced by sequential reduction of acetyl-CoA to acetaldehyde and ethanol. Acetyl-CoA is first converted by an acetaldehyde dehydrogenase into an enzyme-bound thiohemiacetal. The enzyme-bound thiohemiacetal is then reduced to ethanol by an alcohol dehydrogenase [3,4]. To catalyze this reaction E. histolytica has a bifunctional $95 \mathrm{kDa}$ $\mathrm{NAD}^{+}$-dependent and $\mathrm{Fe}^{2+}$-dependent acetaldehyde/alcohol dehydrogenase (EhADH2) $[5,6]$. Antisense inhibition of EhADH2 shows that this enzyme is necessary for the growth and survival of E. histolytica [7]. In addition to its enzymatic activity, EhADH2 and clathrin-coated vesicles have been shown to be involved in the binding and internalization of human holotransferrin [8].

In addition to EhADH2, E. histolytica has at least two enzymes with alcohol dehydrogenase activity called EhADH1 and EhADH3. EhADH1 (EHI_023110) is a NADP(H) dependent homotetrameric class II enzyme with one catalytic zinc ion per monomer and a molecular mass of $39 \mathrm{kDa}$. The enzyme possesses both NADPH-dependent acetaldehyde reductase and $\mathrm{NADP}^{+}$-dependent alcohol dehydrogenase activity and prefers branched chain alcohols (2-propanol) as substrates [9-12]. Two other genes coding for EhADH1-like proteins are present in the genome of E. histolytica with 66\% (EHI_107210) and 29\% (EHI_042260) amino acid identity, respectively.

EhADH3A (EHI_198760) is a 43 kDa NADP-dependent alcohol dehydrogenase with a certain sequence homology to class III microbial alcohol dehydrogenases [13,14]. The enzymatic characterization showed that EhADH3A prefers, in contrast to EhADH1, short-chain unbranched alcohols (butanol followed by propanol and ethanol) [15]. Using comparative proteomics, Davis and colleagues identified ADH3A in higher amounts in the pathogenic E. histolytica HM-1:IMSS strain in comparison to the non-pathogenic E. histolytica strain Rahman or non-pathogenic E. dispar [15]. A total of four genes with homology to ehadh3a/EHI_198760 were identified in the genome. The corresponding amino acid sequences showed 70\% (EHI_192470), 56\% (EHI_125950), and 70\% (EHI_088020/EHI_160670) similarity to EHI_198760 [13-15]. Phylogenetic analyses suggested that the genes encoding EhADH1 and EhADH3 members of E. histolytica and Gram-positive Eubacteria have a common ancestor [16,17].

In contrast to the members of the EhADH1 family, which localize in the cytoplasm, the members of the EhADH2 and EhADH3 family can be located on the cell surface of amoebae and are secreted or shed extracellularly [15,18,19]. However, the function of EhADH1 and EhADH3 within the metabolism of E. histolytica is not clear yet. It is possible that the enzymes are involved in the reduction of free acetaldehyde, which is released from the ADH2 bound thiohemiacetal by hydrolysis [2].

Recently, two non-pathogenic clones $\left(\mathrm{A} 1^{\mathrm{np}}, \mathrm{B} 8^{\mathrm{np}}\right)$ and one pathogenic clone $\left(\mathrm{B} 2^{\mathrm{p}}\right)$, all derived from the E. histolytica isolate HM-1:IMSS, were compared by transcriptome analyses [20]. In this study, 76 genes were identified showing differential expression between clone $\mathrm{A} 1^{\mathrm{np}}$ and clone $\mathrm{B} 2^{\mathrm{p}}$ and 19 genes whose expression differed significantly between B2P and B8 ${ }^{\mathrm{np}}$. In this context, EHI_088020 (ehadh3b ${ }^{a}$ ) and EHI_160760 $\left(\mathrm{ehadh}_{3} \mathrm{~b}^{b}\right)$ genes, which are duplicates in the genome of E. histolytica, were identified as one of the genes expressed in higher concentrations in non-pathogenic clones compared to pathogenic clones $[13-15,20]$. Compared to the pathogenic clone B2p , ehadh3b/b shows an approximately 3-fold higher expression in the non-pathogenic clones A1 ${ }^{\mathrm{np}}$ and B8 ${ }^{\mathrm{np}}(p<0.0001)$.

Interestingly, overexpression of $e h a d h 3 b^{b}$ in the pathogenic clone B2p reduced the ability of the amoebae to form ALAs significantly [20]. However, pathogenicity was not affected by silencing the ehadh3b expression [21].

In the current study, the EhADH3B ${ }^{\mathrm{b}}$ was characterized in detail using overexpression and silencing transfectants with respect to it enzymatic activities and its localization, implying that it is involved in the detoxification of harmful aldehydes present in the intestinal lumen. 


\section{Materials and Methods}

\subsection{E. histolytica Cell Culture and Generation of Transfectants}

E. histolytica trophozoites were cultured axenically in TYI-S-33 medium in plastic culture flasks at $37^{\circ} \mathrm{C}$ [22]. Generation of the clones $\mathrm{A} 1^{\mathrm{np}}, \mathrm{B} 2^{\mathrm{p}}$ and B8 ${ }^{\mathrm{np}}$ derived from cell lines HM-1:IMSS-A and HM-1:IMSS-B has been described elsewhere [20]. Overexpression and silencing transfectants were generated and cultivated as described previously $[20,21]$. For overexpression of ehadh3b $b^{b}$ (EHI_160670) clone $\mathrm{B}^{\mathrm{P}}$ was transfected with the expression plasmid $\mathrm{pNC}$ containing the $e h a d h 3 b^{b}$ gene under control of the E. histolytica lectin promotor $\left(\mathrm{B} 2^{\mathrm{p}} \_\mathrm{pNC}-\right.$ ehadh $\left.3 b^{b}\right)$. As control B2 ${ }^{\mathrm{p}}$ amoebae transfected with $\mathrm{pNC}$ were used (B2 $\left.{ }^{\mathrm{p}} \_\mathrm{pNC}\right)$. For silencing B $8^{\mathrm{np}}$ trophozoites were transfected with the silencing plasmid pSiB containing ehadh3b $b^{b}$ in frame with the trigger region EHI_074080. The cells were cultivated in TYI-S-33 medium containing $20 \mu \mathrm{g} / \mathrm{mL}$ G-418 for 3 weeks. After cloning of the transfectants by limited dilution, the cells were cultivated for at least 4 months without selection until the plasmid was completely lost $\left(\mathrm{B} 8^{\mathrm{np}} \_\right.$Si-ehadh3 $\left.b^{b}\right)$ [21]. B8 ${ }^{\mathrm{np}}$ trophozoites were used as controls. Overexpression and silencing were verified with specific quantitative real time PCR (qPCR) experiments. For localization studies, A1 ${ }^{\text {np }}$ transfectants were used that express EhADH3Bb fused to a c-myc tag. For this, two complementary oligonucleotides coding for a c-myc tag were hybridized, digested with KpnI and BglII and inserted into the KpnI and BamHI restriction sites of pNC (Table S1). Subsequently, ehadh3b $b^{b}$ was cloned into the KpnI/BamHI site.

\subsection{Amplification of adh3b Gene Locus}

The gene loci, containing the ehadh3b genes EHI_088020 (ehadh3b $\left.b^{a}\right)$ and EHI_160670 (ehadh3b $\left.b^{b}\right)$ were analyzed in 15 additional E. histolytica isolates besides to HM-1:IMSS. For this purpose, the regions were amplified and sequenced. The oligonucleotides used for amplification are listed in Table S1 and the amplified regions are shown in Figure 1A. The DNA used comes from the isolates: NIH:200 (isolated in 1949 from a patient with colitis; ATTC 30458) and HK-9 (isolated from a patient with amoebic dysentery (year unknown), ATTC 30458) were both purchased from the American Type Culture Collection (ATTC, Manassas, VA, USA); BM1 and CM2 were kindly provided in 2000 by Prof. E. F. Silva, University of Minas Gerais, Belo Horizonte, Brazil). BNI-1-BNI-10 belong to DNA isolated from stool samples of anonymous E. histolytica carriers. Except for the DNA of HM-1:IMSS, all DNAs used in this study were isolated between 1997-2000 and stored since then at $-80{ }^{\circ} \mathrm{C}$.

\subsection{RNA Extraction and Quantitative Real Time PCR}

Total RNA was isolated using TRIzol reagent (Thermo Fisher Scientific, Schwerte, Germany) as well as RNeasy mini kit (Qiagen, Hilden, Germany) and DNA was digested using DNAse I (Qiagen) according to the manufacturer's instructions. cDNA synthesis was performed using the SuperScript III Reverse Transcriptase system (Thermo Fisher Scientific) as previously described [20].

For qPCR experiments, sense and antisense primers were designed to amplify 80-120 bp fragments of the genes of interest (Table S1). Quantitative amplification was performed as described previously [20]. Two biological duplicates were analyzed. Relative concentrations in gene expression were calculated using the ${ }^{2-\Delta \Delta}$ CT method with Rotor-Gen software. Depending on the experiment, non-transfected amoebae or amoebae transfected with the control plasmid pNC were used for calibration (set to one), and actin was used as the housekeeping gene for normalization. 


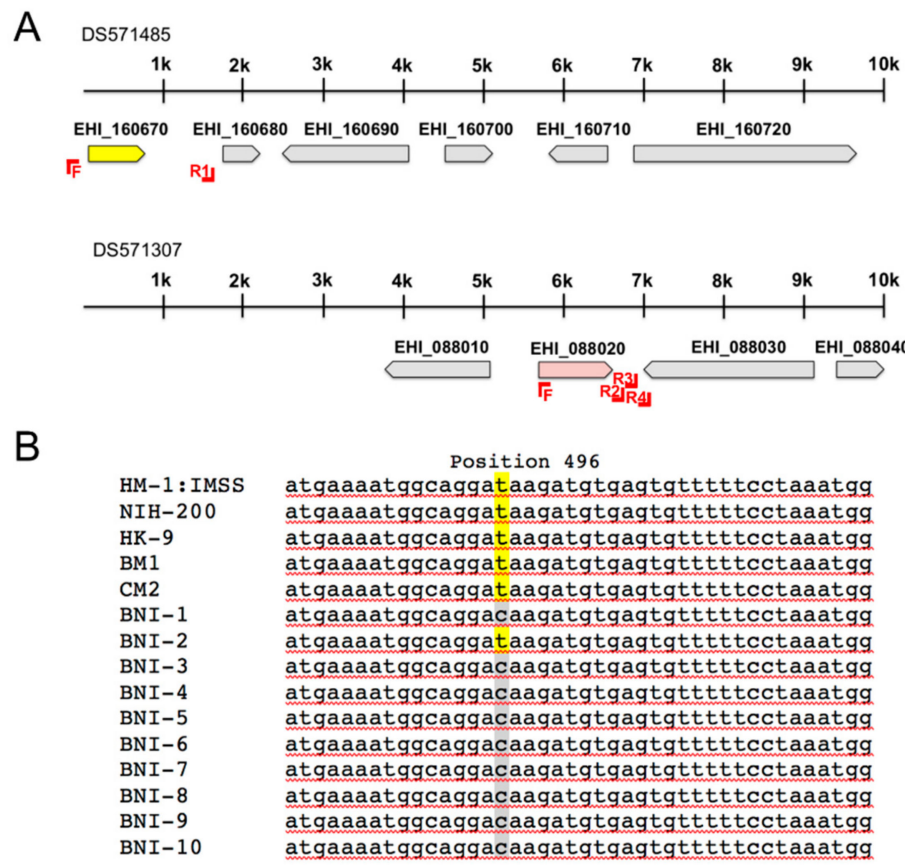

Figure 1. Localization of the EhADH3B coding genes EHI_160670 (ehadh3b $\left.b^{a}\right)$ and EHI_088020 (ehadh3b $\left.{ }^{b}\right)$ in the genome of E. histolytica (AmoebaDB, release 48 beta, 27 August 2020) and sequence analysis of EHI_088020 of different E. histolytica isolates. (A). The gene EHI-160670 (yellow) is located at the beginning of the contig DS571485 and the gene EHI_088020 (red) is located in contig DS571307 at position 5583 to 6731 . The genomic region around the genes EHI_160067 and EHI_088020 was amplified and sequenced in 14 different E. histolytica isolates using the primers shown in A. (B). In EHI_088020 a mutation at position 496 (C-T (yellow)) coding for a stop codon was identified in some of the isolates investigated.

\subsection{Protein Analyses}

To prepare amoebic extracts, $1 \times 10^{6}$ trophozoites were cultivated for $24 \mathrm{~h}$ in $75 \mathrm{~mL}$ culture flasks. Subsequently, the cells were harvested and washed twice with phosphate-buffered saline (NaPBS; $\left.6.7 \mathrm{mM} \mathrm{Na}_{2} \mathrm{HPO}_{4}, 3.3 \mathrm{mM} \mathrm{NaH}_{2} \mathrm{PO}_{4}, 140 \mathrm{mM} \mathrm{NaCl} \mathrm{pH} 7.2\right)$ and sedimented by centrifugation at $400 \times g$ for $2 \mathrm{~min}$ at $4{ }^{\circ} \mathrm{C}$. To minimize proteolysis, $20 \mathrm{M}$ trans-epoxysuccinyl-L-leucyl-amino-(4-guanodino) butane (E64, Merck, Sigma Aldrich, Darmstadt, Germany) was added. E64 was not added if cysteine peptidase (CP) assays were performed. Cells were alternately flash frozen in liquid nitrogen, thawed at room temperature, and vortexed. This was repeated five times. Lysates were centrifuged at $12,000 \times g$ for $10 \mathrm{~min}$ at $4{ }^{\circ} \mathrm{C}$. The supernatants contained NaPBS-soluble proteins. Protein amounts were determined by means of a BCA (bicinchoninic acid) assay (Thermo Fisher Scientific, Langenselbold, Germany).

\subsection{Determination of Hemolytic Activity}

A hemolytic activity assay was performed as described by Biller and colleagues [23]. Briefly, the assay was performed by mixing trophozoites and human $0+$ erythrocytes in a 1:2000 ratio $\left(1.25 \times 10^{5}\right.$ amoebae with $2.5 \times 10^{8}$ erythrocytes per milliliter of NaPBS), followed by incubation for $1 \mathrm{~h}$ at $37^{\circ} \mathrm{C}$. Human $0+$ erythrocytes were provided by the blood bank of the University Medical Center Hamburg-Eppendorf (UKE)-Transfusion Medicine-Germany. After incubation, the cells were sedimented, and hemoglobin released into the supernatant was measured at $570 \mathrm{~nm}$ spectrophotometrically. To determine $100 \%$ hemoglobin release, $2.5 \times 10^{8}$ erythrocytes were lysed in $1 \mathrm{~mL}$ of distilled water. The experiments were performed at least three times in triplicate. Significance was evaluated using the Mann-Whitney U test. 


\subsection{Cysteine Peptidase Assay}

Cysteine peptidase (CP) activity was measured using the synthetic peptide Z-Arg-Arg-pNA (Bachem, Bubendorf, Switzerland) as substrate [24]. One unit of enzymatic activity is defined as the amount of enzyme that catalyzes the generation of $1 \mathrm{mmol} \mathrm{p}$-nitroaniline in $1 \mathrm{~min}$. The assay was performed at least four times in duplicate. To determine the relative $\mathrm{CP}$ activity, the activity of the controls (B2 ${ }^{\mathrm{p}}$ p pNC, $B 8^{\mathrm{np}}$ ) was set to $100 \%$. Significance was evaluated using the Mann-Whitney U test.

\subsection{Erythrophagocytosis}

An erythrophagocytosis assay was performed as described by Biller and colleagues [23]. Human erythrocytes and trophozoites were washed twice with serum-free TYI-S-33 medium. $2 \times 10^{8}$ erythrocytes and $2 \times 10^{5}$ amoebae were mixed to a final volume of $400 \mu \mathrm{L}$, in serum-free TYI-S-33 medium and incubated in parallel at $37^{\circ} \mathrm{C}$ for $30 \mathrm{~min}$. To stop phagocytosis and lyse non-phagocytosed erythrocytes, $1 \mathrm{~mL}$ of distilled water was added, twice. Trophozoites were washed twice with NaPBS. Average numbers of ingested erythrocytes were quantified by measuring the absorbance at $397 \mathrm{~nm}$ after trophozoite lysis in $90 \%$ formic acid. The experiments were performed three times in triplicate. Significance ( $p$-values) was evaluated using the Mann-Whitney U test.

\subsection{Determination of Cell Division Rate}

To determine cell division rate, $1 \times 10^{4}$ trophozoites of each cell line were seeded in a $25 \mathrm{~mL}$ culture flask, and cultivated for $48 \mathrm{~h}$. The cell division rate in $24 \mathrm{~h}$ was determined three times in triplicate for each cell line. Significance was evaluated using Student's unpaired $t$ test.

\subsection{Motility}

The Image (NIH; National Institute of Health, Bethesda, Maryland, USA) program was used to determine motility. For this purpose, a picture was taken every $30 \mathrm{~s}$ using a microscope (BZ9000; Keyence, Neu-Isenburg, Germany). The images were imported as an image sequence into the program. To determine the accumulated distance of the amoebae, the Manual Tracking Plugin and the Chemotaxis Plugin were used.

\subsection{Determination of Amoeba Sizes}

To determine amoeba size, the circumference of 180 trophozoites of each cell line was measured using a microscope (BZ9000; Keyence, Neu-Isenburg, Germany). Significance was evaluated using the Mann-Whitney U test.

\subsection{Recombinant Expression in E. coli and Purification of the Recombinant EhADH3B ${ }^{b}$}

The complete coding sequences of the ehadh3b ${ }^{b}$ (EHI_160670) gene was amplified by PCR using E. histolytica DNA of the isolate HM-1:IMSS and the oligonucleotides described in Table S1 and cloned in frame into the expression vector pGEX-6P-2 (Merck, GE Healthcare, Darmstadt, Germany) using BamHI and EcoRI cleavage sites to generate a fusion protein with an N-terminal glutathione-S-transferase (GST) tag and recognition sequence for site-specific cleavage by PreScission ${ }^{\text {TM }}$ Protease (Merck, GE Healthcare, Darmstadt, Germany). Recombinant expression was performed in E. coli BL21 (DE3) [pAPlacI $\mathrm{I}^{\mathrm{Q}}$. After transformation of $E$. coli with the plasmid, the bacteria were transferred into $25 \mathrm{~mL}$ LB medium supplemented with $100 \mu \mathrm{g} / \mathrm{mL}$ ampicillin and $50 \mu \mathrm{g} / \mathrm{mL}$ kanamycin, and grown overnight at $37^{\circ} \mathrm{C}$. An aliquot was transferred to $500 \mathrm{~mL}$ LB medium containing ampicillin and kanamycin, and grown at $37^{\circ} \mathrm{C}$ until $\mathrm{OD}_{600}$ reached 0.6. After inducing the expression with a final concentration of $1 \mathrm{mM}$ IPTG, bacteria were grown overnight at $17^{\circ} \mathrm{C}$. Cells were lysed by sonication, centrifuged at $4000 \times g$ at $4{ }^{\circ} \mathrm{C}$ for $15 \mathrm{~min}$ and subsequently the supernatant containing the recombinant protein was subjected to glutathione sepharose chromatography (Merck, GE Healthcare, Darmstadt, Germany). An on-column 
cleavage with HRV-3C protease was performed at $4{ }^{\circ} \mathrm{C}$ overnight. The tagged protein, containing a $3 \mathrm{C}$ protease recognition site is cleaved off, while the GST moiety remains bound to glutathione sepharose. The $3 \mathrm{C}$ protease also carries a GST tag resulting in pure target protein in the flow-through.

\subsection{Size Exclusion Chromatography}

For further purification and determination of the size of the native protein, size exclusion chromatography was performed on a HiLoad 16/60 Superdex prep grade column using the ÄKTA ${ }^{\mathrm{TM}}$ pure liquid chromatograph (GE Healthcare, Darmstadt, Germany) and $50 \mathrm{mM}$ Tris, $150 \mathrm{mM} \mathrm{NaCl}$, $10 \mathrm{mM}$ EDTA, $1 \mathrm{mM}$ DTT, 10\% glycerol, pH 8.0 as running buffer.

\subsection{Thermal Stabilization Assay}

The thermal stabilization assay detects the unfolding of a target protein induced by a step-wise elevation of the temperature. In presence of different additives and the fluorophore Sypro ${ }^{\circledR}$ Orange (Merck, Sigma Aldrich, Darmstadt, Germany) the recombinant protein was heated step by step from $20{ }^{\circ} \mathrm{C}$ to $90{ }^{\circ} \mathrm{C}$ in the Light Cycler ${ }^{\circledR}$ II (Roche, Mannheim, Germany). The fluorophore is quenched in aqueous solution. As the temperature increases, the protein unfolds, exposing hydrophobic areas to which SYPRO Orange can bind, thereby emitting fluorescence. The inflection point of the protein melting curve marks the "melting point" of the protein. Depending on the reaction conditions the protein might be more or less stable, and thus unfolds at lower or higher temperatures, respectively. Binding of a ligand can stabilize a protein and therefore cause a shift in melting temperature. The assay was performed in a 96 well plate in triplicate in a total volume of $25 \mu \mathrm{L}$ containing reaction buffer $(50 \mathrm{mM}$ Tris- $\mathrm{HCl} \mathrm{pH} 7.5,150 \mathrm{mM} \mathrm{NaCl}, 1 \mathrm{mM}$ EDTA, 1 mM DTT), $2.5 \mu \mathrm{g}$ recombinant protein EhADH3B ${ }^{\mathrm{b}}, 2$ $\mu \mathrm{L}$ SYPRO Orange (1:80 dilution) and either absence or presence of various metal ions $\left(\mathrm{Mg}^{2+}, \mathrm{Mn}^{2+}\right.$, $\mathrm{Ni}^{2+}, \mathrm{Ca}^{2+}, \mathrm{Zn}^{2+}$ and $\mathrm{Fe}^{3+}$ ) at a concentration of $2 \mathrm{mM}$.

\subsection{Enzymatic Assays}

Aldehyde/alcohol dehydrogenase activity was measured indirectly by evaluating oxidation or reduction of $\operatorname{NAD}(\mathrm{P})(\mathrm{H})$ photometrically at $340 \mathrm{~nm}$ in triplicate in 96-well plates (lumox ${ }^{\circledR}$, Sarstedt, Nümbrecht, Germany) using an MRX ELISA reader (Dynex Technologies, Chantilly, VA, USA).

The assays were performed depending on the $\mathrm{pH}$ in a $100 \mathrm{mM}$ glycine buffer $(\mathrm{pH} 8,9), 100 \mathrm{mM}$ Tris buffer $(\mathrm{pH} 7,7.4,6)$ at a total volume of $200 \mu \mathrm{L}$ containing $4 \mu \mathrm{g}$ recEhADH3B ${ }^{\mathrm{b}}, 0.1-100 \mathrm{mM}$ substrate, and $0.7 \mathrm{mM} \mathrm{NAD}(\mathrm{P}) \mathrm{H} / \mathrm{NAD}(\mathrm{P})$. The amount of enzyme which is needed to catalyze the oxidation or reduction of $1 \mu \mathrm{mol}$ of $\mathrm{NAD}(\mathrm{P})(\mathrm{H})$ is defined as one unit. The following substrates were tested: Methanol, ethanol, 1-propanol, 2-propanol, butanol, formaldehyde (methanal), acetaldehyde (ethanal), propionaldehyde (propanal) and butyraldehyde (butanal). EDTA $(10 \mathrm{mM})$ was incubated with the enzyme for $1 \mathrm{~h}$ on ice. To remove EDTA, the enzyme solution was dialysed against an EDTA-free buffer. Different metal ions at a concentration of $1 \mathrm{mM}$ were added to the dialyzed enzyme solution and incubated for $1 \mathrm{~h}$ on ice. Subsequently acetaldehyde-dependent oxidation of $\mathrm{NAD}(\mathrm{P}) \mathrm{H}$ was measured. The metal-free and dialyzed recEhADH3B ${ }^{\mathrm{b}}$ served as negative control. As positive control the $\mathrm{NAD}(\mathrm{H})$-dependent alcohol dehydrogenase from Saccharomyces cerevisiae (Merck, Sigma Aldrich, Darmstadt, Germany) was used.

\subsection{Generation of Polyclonal Antibodies}

EhADH3B ${ }^{b}$ specific antibodies were generated by injecting $100 \mu \mathrm{g}$ of recombinant protein in complete Freund's adjuvant (Merck, GE Healthcare, Darmstadt, Germany) into BALB/c mice, followed by two booster injections, at 2 weeks intervals, with $100 \mu \mathrm{g}$ of recombinant protein in incomplete Freund's adjuvant (Merck, GE Healthcare, Darmstadt, Germany). After blood collection, the sample was centrifuged at $1400 \times g$ for $10 \mathrm{~min}$ and the serum was frozen at $-20^{\circ} \mathrm{C}$. 


\subsection{Immunofluorescence Assays (IFA)}

Freshly harvested and NaPBS-washed amoebae $\left(5 \times 10^{5}\right)$ were fixed in $3 \%$ paraformaldehyde in NaPBS. For intracellular staining cells were permeabilized with NaPBS containing $0.2 \%$ saponin. Free aldehyde groups were blocked by subsequent incubation with $50 \mathrm{mM}$ ammonium chloride in NaPBS (with and without $0.2 \%$ saponin, respectively), followed by incubation with blocking buffer (NaPBS supplemented with $2 \%$ fetal calf serum) for $10 \mathrm{~min}$. The trophozoites were subsequently incubated with the primary antibody (polyclonal $\alpha$-EhADH3B ${ }^{b}$ mouse serum or $\alpha$-c-myc monoclonal antibody (Merck, GE Healthcare, Darmstadt, Germany); diluted 1:200 in NaPBS +/-saponin), washed three times with NaPBS, and finally incubated in the dark with 1:400 dilutions of Alexa Fluor 594 goat $\alpha$-mouse or Alexa Fluor 488 goat $\alpha$-mouse (Thermo Fisher Scientific, Invitrogen, Darmstadt, Germany). After addition of Hoechst 33,342 (1 $\mu \mathrm{g} / \mathrm{mL}$ final concentration; Merck, Sigma Aldrich, Darmstadt, Germany) for $10 \mathrm{~min}$ and additional three washes with NaPBS, the amoebae were analyzed by fluorescence microscopy (Axio Images M2, Zeiss, Germany). Light and confocal fluorescence microscopy were performed using the Axio imager M2 (Zeiss) and the IX81 (Olympus) microscope, respectively.

\section{Results}

\subsection{In Silico Analysis of E. histolytica ADHs}

Four different alcohol dehydrogenases of E. histolytica have been described and characterized (Table 1). However, more than 20 ehadh genes have been predicted [25]. To obtain a complete picture of the total number of ehadh genes present in the genome of E. histolytica, an in silico analysis using AmoebaDB (release 48 beta, 27 August 2020) and BlastP search was performed.

Table 1. Alcohol dehydrogenases of Entamoeba histolytica.

\begin{tabular}{|c|c|c|c|}
\hline $\begin{array}{l}\text { Accession Number } \\
\text { (AmoebaDB) }\end{array}$ & Length (aa) & ADH Type (Homology) & Reference \\
\hline \multicolumn{4}{|l|}{ EhADH1 } \\
\hline EHI_023110 & 366 & $\begin{array}{l}\text { Type 1, } \\
\text { Zn-dependent }\end{array}$ & {$[11,12]$} \\
\hline EHI_042260 & 343 & $\begin{array}{l}\text { Type 1, } \\
\text { Zn-dependent }\end{array}$ & \\
\hline EHI_107210 & 367 & $\begin{array}{l}\text { Type 1, } \\
\text { Zn-dependent }\end{array}$ & \\
\hline \multicolumn{4}{|l|}{ EhADH2 } \\
\hline EHI_150490 & 870 & Bifunctional ADHE & {$[5-7,18,26,27]$} \\
\hline EHI_160940\# & 870 & Bifunctional ADHE & \\
\hline EHI_024240 & $829^{1}$ & Bifunctional ADHE & \\
\hline \multicolumn{4}{|l|}{ EhADH3 } \\
\hline EHI_198760 (EhADH3A) & 384 & $\mathrm{Fe}-\mathrm{ADH}$ & [13-15] \\
\hline EHI_088020 (EhADH3B $\left.{ }^{a}\right)$ & 382 & Fe-ADH & [20] \\
\hline EHI_160670 (EhADH3B $\left.{ }^{b}\right)$ & $382^{2}$ & Fe-ADH & {$[20]$} \\
\hline EHI_125950 (EhADH3C) & 383 & $\mathrm{Fe}-\mathrm{ADH}$ & \\
\hline EHI_192470 (EhADH3D) & 382 & Fe-ADH & \\
\hline \multicolumn{4}{|l|}{ Undetermined } \\
\hline EHI_000410 & 360 & Fe-ADH superfamily & \\
\hline EHI_166490 & $419^{1}$ & $\begin{array}{l}\text { Bifunctional ADHE } \\
\text { EHI_150490: 52\% (C-terminus) }\end{array}$ & \\
\hline
\end{tabular}

\footnotetext{
${ }^{1}$ Incompletely sequenced (AmoebaDB, release 48 beta, 27 August 2020), ${ }^{2}$ see this study.
} 
Three members belonging to the EhADH1 family could be identified (Table 1). The already described gene EHI_023110 encodes for an EhADH1 of 366 amino acids and it is 66\% identical to EHI_107210 (367 aa) and 24\% identical to EHI_042260 (343 aa) (Table 2). All three ADHs have homology to Zn-dependent type 1 ADHs.

Table 2. Amino acid sequence identity of the various alcohol dehydrogenases of E. histolytica.

\begin{tabular}{|c|c|c|c|c|c|}
\hline \multicolumn{6}{|l|}{ EhADH1 } \\
\hline & EHI_023110 & EHI_042260 & EHI_107210 & & \\
\hline EHI_023110 & $\times$ & $24 \%$ & $66 \%$ & & \\
\hline EHI_042260 & & $x$ & $25 \%$ & & \\
\hline \multirow{2}{*}{\multicolumn{6}{|c|}{$\begin{array}{c}\text { EHI_107210 } \\
\text { EhADH2 }\end{array}$}} \\
\hline & & & & & \\
\hline & EHI_150490 & EHI_160940 & EHI_024240 ${ }^{1}$ & & \\
\hline EHI_150490 & $\times$ & $99 \%$ & $97 \%$ & & \\
\hline EHI_160940 & & $x$ & $97 \%$ & & \\
\hline \multirow{2}{*}{\multicolumn{6}{|c|}{$\begin{array}{c}\text { EHI_024240 } \\
\text { EhADH3 }\end{array}$}} \\
\hline & & & & & \\
\hline & EHI_088020 & EHI_160670 & EHI_198760 & EHI_125950 & EHI_192470 \\
\hline EHI_088020 & $\times$ & $100 \%$ & $70 \%$ & $55 \%$ & $78 \%$ \\
\hline EHI_160670 & & $\times$ & $70 \%$ & $55 \%$ & $78 \%$ \\
\hline EHI_198760 & & & $x$ & $55 \%$ & $69 \%$ \\
\hline EHI_125950 & & & & $\times$ & $57 \%$ \\
\hline EHI_192470 & & & & & $\times$ \\
\hline
\end{tabular}

In AmoebaDB three genes are annotated (EHI_150490, EHI_160940,EHI_024240), which encode for a bifunctional EhADH2 with homology to ADHE of Escherichia coli. EHI_150490 and EHI_160940 encoding for an EhADH2 which consists of 870 amino acids (99\% identity). The 3'-end of EHI_024240 is not correctly annotated (AmoebaDB, release 48 beta, 27 August 2020). Therefore, only the first 787 amino acids can be used for a sequence comparison of EHI_024240 with EHI_150490 and EHI_160940. This indicates a sequence identity of $97 \%$, because of a 14 amino acid deletion of EHI_024240 (Tables 1 and 2).

Beside the already described EhADH3 coding genes EHI_198760 (ehadh3a) and EHI_088020 $\left(\right.$ ehadh $\left.3 b^{a}\right)$, which is present in the genome as a gene duplicate (EHI_160670; ehadh3b $b^{b}$ (Figure 1A), two additional genes, EHI_192470 (ehadh3c) and EHI_125950 (ehadh3d), which also belong to this family could be identified. These genes, all encode EhADH3 with a length between 380-384 amino acids. The EhADH3 proteins are between 55\% and 78\% identical to each other (Tables 1 and 2 ). All have the amino acids aspartic acid and three histidines predicted for metal binding (for EhADH3B ${ }^{\mathrm{b}}: \mathrm{D}_{196}$, $\mathrm{H}_{200}, \mathrm{H}_{269}, \mathrm{H}_{263}$ ). The typical, conserved N-terminal type III ADH domain GGGSXXD (for EhADH3B ${ }^{\mathrm{b}}$ : $\left.\mathrm{G}_{93} \mathrm{G}_{94} \mathrm{G}_{95} \mathrm{~S}_{96} \mathrm{D}_{99}\right)$ which is involved in the binding of the $\mathrm{NAD}(\mathrm{P})^{+}$cofactor, is also present in all EHADH3 proteins [28].

As mentioned above, ehadh3b exists as a gene duplicate in the genome of E. histolytica (EHI_088020

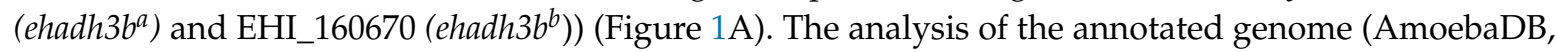
release 48 beta, 27 August 2020); however, showed that the gene EHI_160670 (ehadh3b $\left.{ }^{b}\right)$ is located at the 5' end of the contig DS571485. To verify whether the contig contains the complete gene or not, the genomic region was amplified with a forward primer derived from the 5'-end of EHI_088020 (ehadh3b $5^{a}$ ) and a reverse primer derived from the intergenic region between EHI_160670 and the 3'-located gene EHI_160680. Obtaining a specific amplicon and its subsequent sequencing confirmed that both genes

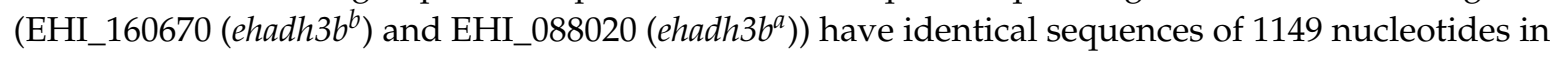
length (Figure 1A). However, a further sequence analysis of all three HM-1:IMSS derived E. histolytica clones (A1 $\left.{ }^{\mathrm{np}}, \mathrm{B} 2^{\mathrm{p}}, \mathrm{B} 8^{\mathrm{np}}\right)$ revealed that EHI_088020 (ehadh3b $\left.{ }^{a}\right)$ contains a mutation at position 496 coding for a stop codon (TAA). Thus, only EHI_160670 $\left(\right.$ ehadh3b $\left.b^{b}\right)$ appears to express an enzymatically active EhADH3B as only this protein contains all relevant parts required for enzymatic activity. 
To investigate whether this is a mutation with general validity, the DNA of 14 other E. histolytica isolates was analyzed. It was found that the laboratory isolates NIH-200 and HK-9 and two isolates of Brazilian origin contain, similarly as HM-1:IMSS, the mutation at position 496 of EHI_088020 $\left(\right.$ ehadh $\left.3 b^{a}\right)$, which codes for a stop codon. In contrast, no stop codon was detected in the EHI_088020 $\left(\right.$ ehadh $\left.3 b^{a}\right)$ gene of 9 out of the 10 samples from the BNITM. In only one of these natural isolates (BNI-2) the corresponding mutation could be detected (Figure 1B).

\subsection{Phenotypical Characterization of ehadh $3 b^{b}$ Overexpressing and Silencing Transfectants}

Comparative transcriptome analyses have shown that $e h a d h 3 b^{b}$ was approximately three times higher expressed in non-pathogenic amoebae $A 1^{\mathrm{np}}$ and B8 ${ }^{\mathrm{np}}$ than in pathogenic amoebae B2p [20]. Furthermore, it has been shown that the overexpression of $e h a d h 3 b^{a}$ reduces the ability of pathogenic amoebae to induce ALAs. Conversely, the silencing of $e h a d h 3 b^{b}$ did not increase the virulence of non-pathogenic amoebae. To assign the expression of the ehadh $3 b^{a}$ gene directly to a phenotype, transfectants were used whose expression of $e h a d h 3 b^{b}$ was either enhanced or silenced [20,21].

The analysis of the transcriptomes of the B2 $\mathrm{p}$ transfectants overexpressing ehadh3b $\left(B 2{ }^{p}\right.$ _pNC-ehadh $\left.3 b^{b}\right)$ showed that the expression of the other EhADH3 family members is not affected. In total, overexpression only affects the expression of four other genes significantly ( $\geq 2$-fold, $\leq 0.05$ padjusted). These are two AIG (avrRpt2-induced gene) family members of unknown function and two hypothetical proteins (Table 3 and S2).

Table 3. Expression levels of genes differentially expressed between $\mathrm{B} 2^{\mathrm{P}}$ _pNC transfectants (control)

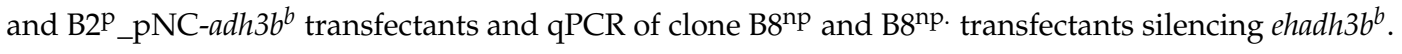

\begin{tabular}{|c|c|c|c|c|c|c|c|}
\hline \multirow[t]{2}{*}{ Gene } & \multicolumn{2}{|c|}{ Expression Level } & \multirow[t]{2}{*}{$\begin{array}{c}\text { Fold } \\
\text { Change }\end{array}$} & \multirow[t]{2}{*}{ Padj } & \multirow[t]{2}{*}{ Product } & \multicolumn{2}{|r|}{ qPCT } \\
\hline & $\mathrm{B}^{\mathrm{p}}{ }_{-}^{\mathrm{p} N C}$ & 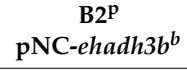 & & & & $B 8^{\text {np }}$ & B8 ${ }^{\text {np-Si-ehadh } 3 b^{b}}$ \\
\hline EHI_088020/EHI_160670 & $0 \quad 312$ & 4081 & 13 & $9.4 \times 10^{-34}$ & $\mathrm{EhADH}_{3} \mathrm{~B}^{\mathrm{a} / \mathrm{b}}$ & 1 & $0.02 \pm 0.008^{* * * *}$ \\
\hline EHI_198760 & 10,423 & 12,377 & 1.2 & 1 & EhADH3A & 1 & $0.935 \pm 0.18$ \\
\hline EHI_125950 & 6319 & 6578 & 1.0 & 1 & EhADH3C & 1 & $0.465 \pm 0.12^{* * * *}$ \\
\hline EHI_192470 & 128 & 132 & 1.0 & 1 & EhADH3D & 1 & $0.01 \pm 0^{* * * *}$ \\
\hline EHI_022490 & 15 & 52 & 3.5 & 0.0033 & $\begin{array}{l}\text { AIG family } \\
\text { protein }\end{array}$ & & \\
\hline EHI_144490 & 309 & 746 & 2.4 & 0.0033 & $\begin{array}{l}\text { Hypothetical } \\
\text { protein }\end{array}$ & & \\
\hline EHI_176590 & 28 & 96 & 3.4 & 0.0046 & $\begin{array}{l}\text { AIG family } \\
\text { protein }\end{array}$ & & \\
\hline EHI_062960 & 10 & 37 & 3.7 & 0.0205 & $\begin{array}{l}\text { Hypothetical } \\
\text { protein }\end{array}$ & & \\
\hline
\end{tabular}

Silencing of $e h a d h 3 b^{b}$ was performed in the non-pathogenic clone B8 ${ }^{\text {np }}$. In this case, the entire open reading frame of 1149 base pairs was fused to the trigger sequence [21]. The influence of silencing was analyzed by qPCR for the other members of the ehadh3 gene family. In contrast to the overexpression, the silencing of $e h a d h 3 b^{b}$ expression has also an effect on ehadh3c and ehadh3d expression. While the detected ehadh3c RNA amount is reduced by about $50 \%$, the expression of the ehadh $3 d$ gene is completely silenced. With 78\%, EhADH3D also shows the greatest similarity to EhADH3B ${ }^{\mathrm{b}}$ (Tables 2 and 3). No influence on ehadh3a expression was observed.

The phenotype of overexpression and silencing transfectants was analyzed subsequently. This included the determination of hemolytic and cysteine peptidase (CP) activity, erythrophagocytosis, doubling time, movement and size (Figure 2A-F). Significant differences could only be found for the silencing transfectants. On the one hand, these have an approximately $30 \%$ significantly lower relative CP activity (Figure $2 \mathrm{~B}$ ) and they move faster (342 $\pm 112 \mu \mathrm{M}$ accumulated distance in $10 \mathrm{~min}$ ) than the $\mathrm{B}^{\mathrm{np}}$ controls $(279 \pm 126 \mu \mathrm{M}$ accumulated distance in $10 \mathrm{~min})$ (Figure 2E). 


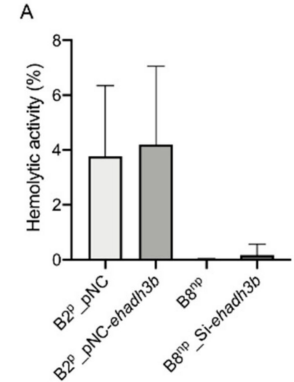

D

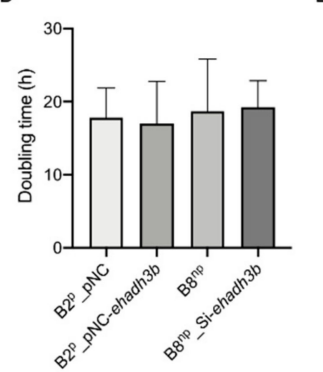

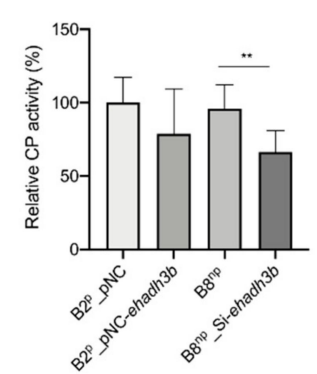

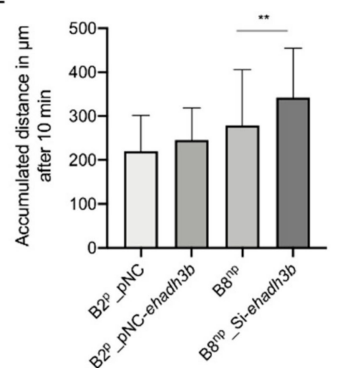

C
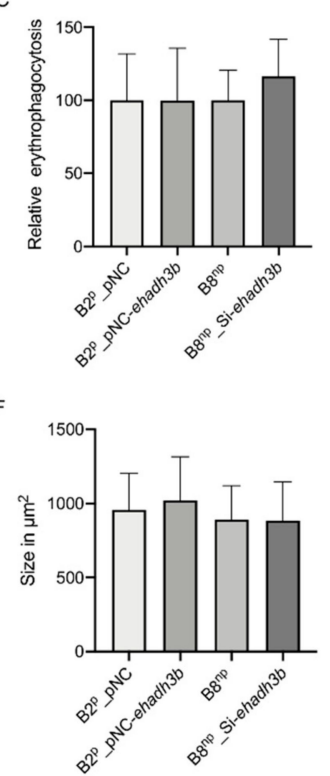

Figure 2. Phenotypical characterization of $e h a d h 3 b^{b}$ overexpressing and silencing transfectants. Hemolytic activity (A), cysteine peptidase activity (B), erythrophagocytosis (C), doubling time (D), motility (E), and size (F) was determined of $\mathrm{B}^{\mathrm{P}}$ transfectants overexpressing ehadh $^{2} b^{b}$ in comparison to the respective control amoebae transfected with $\mathrm{pNC}$ and of $\mathrm{B} 8^{\mathrm{np}}$ transfectants were expression of ehadh $3 b^{b}$ was silenced using B8 ${ }^{\text {np }}$ trophozoites as control. ${ }^{* *} p<0.01$.

\subsection{Recombinant Expression and Determination of Co-Factor and Enzymatic Characterization of EhADH3B}

To determine the enzymatic activity of EhADH3B ${ }^{b}$ the protein was recombinantly expressed in E. coli (recEhADH3B ${ }^{\mathrm{b}}$ ). Expression of $e h a d h 3 b^{b}$ from the plasmid pGEX-6P-2 resulted in the production of the protein containing an N-terminally fused glutathione-S-transferase (GST). After purification and proteolytic cleavage of the GST, SDS-PAGE revealed the presence of a relatively pure protein with a molecular weight of about $43 \mathrm{kDa}$ (Figure 3A), which is in good agreement with the calculated molecular weight of the target protein of approximately $42.6 \mathrm{kDa}$. Size exclusion chromatography indicated that the protein is present as a dimer under physiological conditions (Figure 3B).

To identify a putative metal cofactor of recEhADH3B ${ }^{b}$ a thermal stabilization assay with recEhADH3B ${ }^{b}$ was performed. A thermal stabilization of the protein in this assay (i.e., higher melting point) in presence of a cofactor compared to the protein alone can be interpreted as an indication for binding of the respective cofactor to the target protein, thereby stabilizing the tertiary and/or quaternary protein structure. Six different metal ions $\left(\mathrm{Fe}^{3+}, \mathrm{Mg}^{2+}, \mathrm{Mn}^{2+}, \mathrm{Ni}^{2+}, \mathrm{Ca}^{2+}, \mathrm{Zn}^{2+}\right)$ were tested as putative cofactors in a concentration of $2 \mathrm{mM}$. In the presence of both $\mathrm{Ni}^{2+}$ and $\mathrm{Zn}^{2+}$ a significant shift in the protein melting temperature (inflection point of the melting curve) of about $+3{ }^{\circ} \mathrm{C}$ compared to the control without metal ions was detected indicating that these two ions can be coordinated by recEhADH3B ${ }^{\mathrm{b}}$ (Figure $3 \mathrm{C}$ ). 

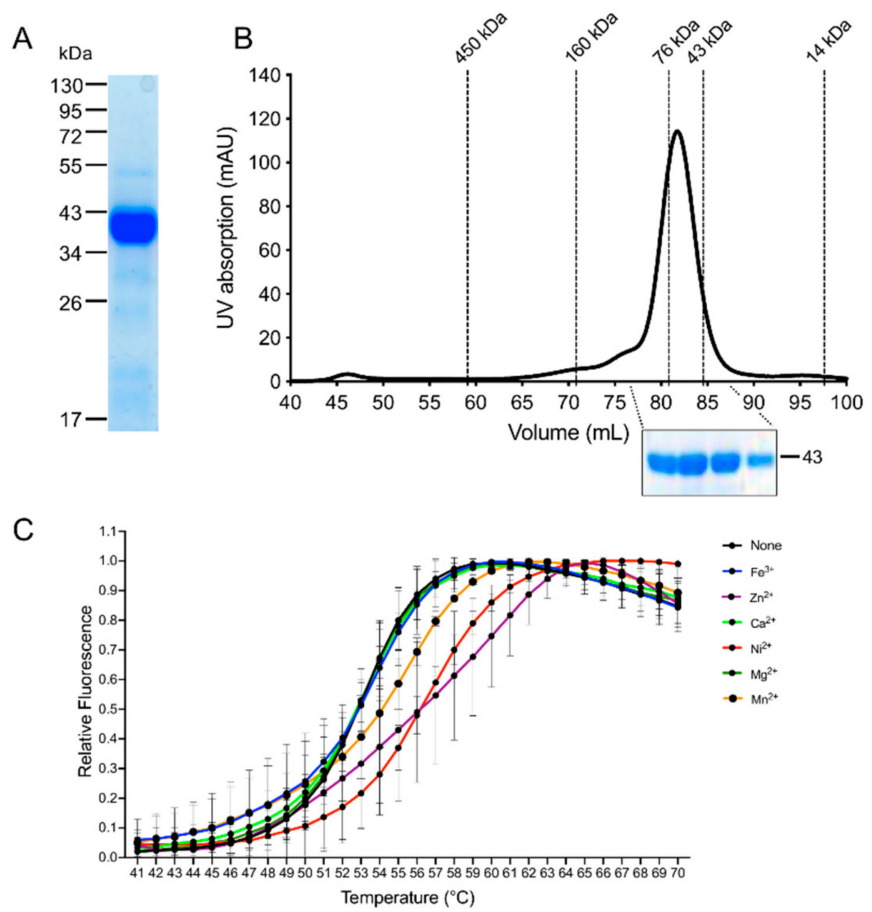

Figure 3. Recombinant expression, investigation of the oligomeric state and putative metal cofactor binding of EhADH3B ${ }^{b}$. (A). ehadh3b $b^{b}$ was recombinantly expressed in E. coli as a GST-fusion protein and purified using affinity chromatography. After purification and cleavage of the GST tag, the recombinant $\mathrm{ADH}_{3} \mathrm{~B}^{\mathrm{b}}\left(\mathrm{recADH}_{3} \mathrm{~B}^{\mathrm{b}}\right.$ ) can be displayed as a $43 \mathrm{kDa}$ protein band after SDS-PAGE and Coomassie staining. (B). Size exclusion chromatography of recADH3B ${ }^{\mathrm{b}}$ was performed on a HiLoad 16/60 Superdex prep grade column in a buffer containing $50 \mathrm{mM}$ Tris, $150 \mathrm{mM} \mathrm{NaCl}, 10 \mathrm{mM}$ EDTA, $1 \mathrm{mM} \mathrm{DTT}, 10 \%$ glycine, $\mathrm{pH}$ 8.0. Elution peaks of standard proteins are indicated by dotted lines in the elution profile of the target protein (black solid line). An elution peak of the target protein at $82 \mathrm{~mL}$ and subsequent detection of the protein in the respective elution fractions by SDS-PAGE indicates that recADH3 $\mathrm{B}^{\mathrm{b}}$ is present as a dimer in solution. (C). Thermal stabilization assay for the determination of the putative metal cofactor of recEhADH3B $\mathrm{B}^{\mathrm{b}}$ by addition of different metal ions at a concentration of $2 \mathrm{mM}$. The melting curve of recEhADH3B $\mathrm{B}^{\mathrm{b}}$ without addition of metal ions was used as a control for the assay. The relative fluorescence is displayed as a function of temperature.

In a next step the catalytic activity of recEhADH3B ${ }^{\mathrm{b}}$ was determined with a range of substrates (methanol, ethanol, 1-propanol, 2-propanol, butanol, formaldehyde, acetaldehyde, propionaldehyde, and butyraldehyde, between $0.1-100 \mathrm{mM}$, depending on the substrate) in the presence of $0.7 \mathrm{mM}$ NADP $(\mathrm{H})$ at $\mathrm{pH} 7.4$ (Figure $4 \mathrm{~A}$ ). Before the assay the recEhADH3B ${ }^{\mathrm{b}}$ was first incubated with $10 \mathrm{mM}$ EDTA to remove all metal ions from the active center. After dialysis the protein was incubated with $1 \mathrm{mM} \mathrm{NiCl}\left(1 \mathrm{~h} / 4^{\circ} \mathrm{C}\right)$ and the enzyme activity was determined. In none of the tested alcoholic substrates the recEhADH3 $\mathrm{B}^{\mathrm{b}}$ was able to catalyze the in vitro oxidation, even in the presence of higher alcohol concentrations (Figure 4A). The highest activity could be determined when acetaldehyde was used as substrate (Figure $4 \mathrm{~A}$ ). The specific activity of the purified recEhADH3B ${ }^{\mathrm{b}}$ was $24 \pm 2.0 \mathrm{mU} / \mathrm{mg}$ with a Km of $30.84 \mathrm{mM}$ [95\% confidence interval (CI) 16.21-60.54] and a Vmax of $0.24 \mu \mathrm{mol} \mathrm{min}^{-1} \mathrm{mg}^{-1}$ [95\% CI 0.18 to 0.33] for acetaldehyde (Figure 4B-D). A lower activity could also be measured in the presence formaldehyde $(50 \mathrm{mM})$ with a specific activity of $13 \pm 4.9 \mathrm{mU} / \mathrm{mg}$, a $\mathrm{Km}$ of $63.7 \mathrm{mM}[95 \%$ CI 25.3 to 267.4] and a Vmax of $0.21 \mu \mathrm{mol} \mathrm{min}^{-1} \mathrm{mg}^{-1}$ [95\% CI 0.14 to 0.54] (Figure 4A,E-G). However, an aldehyde reductase activity was not observed using NADH as cofactor. 

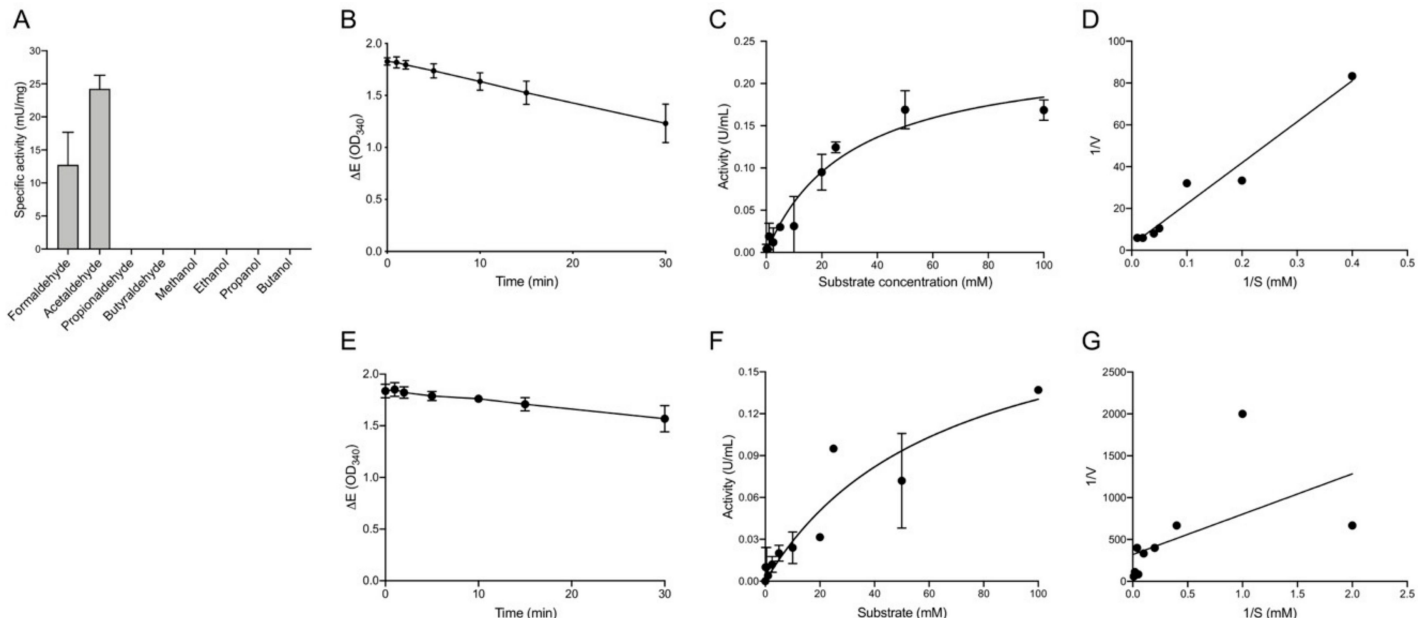

Figure 4. Determination of the enzymatic activity of recEhADH3B ${ }^{\mathrm{b}}$. (A). The catalytic activity of recEhADH3B ${ }^{b}$ was determined with a range of substrates (formaldehyde $(50 \mathrm{mM})$, acetaldehyde $(20 \mathrm{mM})$, propionaldehyde and butyraldehyde, methanol, ethanol, propanol, butanol (all $100 \mathrm{mM}$ )) in the presence of $0.7 \mathrm{mM} \mathrm{NADP}(\mathrm{H})$ at $\mathrm{pH}$ 7.4. (B-D) Enzyme kinetic of recEhADH3B ${ }^{\mathrm{b}}$ using acetaldehyde as substrate. (E,F) Enzyme kinetic of recEhADH3B ${ }^{\mathrm{b}}$ using formaldehyde as substrate. (B,E) Time dependence of enzymatic activity; (C,F) Michaelis-Menten plot; (D,G) Lineweaver-Burk plot.

To investigate whether metal ions other than $\mathrm{Ni}^{2+}$ can serve as cofactors, the EDTA-treated and dialyzed recEhADH3B ${ }^{b}$ was incubated with the metal ions $\mathrm{Zn}^{2+}, \mathrm{Ca}^{2+}, \mathrm{Mg}^{2+}$ and $\mathrm{Na}+($ each $1 \mathrm{mM})$. The subsequent enzymatic assay showed an $86 \%$ activity using $\mathrm{Zn}^{2+}$ compared to the activity in the presence of $\mathrm{Ni}^{2+}(100 \%)$. In the presence of $\mathrm{Ca}^{2+}$ the relative activity is $41 \%$ and in the presence of $\mathrm{Mg}^{2+}$ and $\mathrm{Na}^{+}$only $27 \%$ (Figure $5 \mathrm{~A}$ ). The highest relative activity was observed at $\mathrm{pH}$ values of 7.0 and 7.4. The activity is reduced by about $30 \%$ at $\mathrm{pH} 8$, by $60 \%$ at $\mathrm{pH} 6$ and by $70 \%$ at $\mathrm{pH} 9$ (Figure $5 \mathrm{~B}$ ).

A

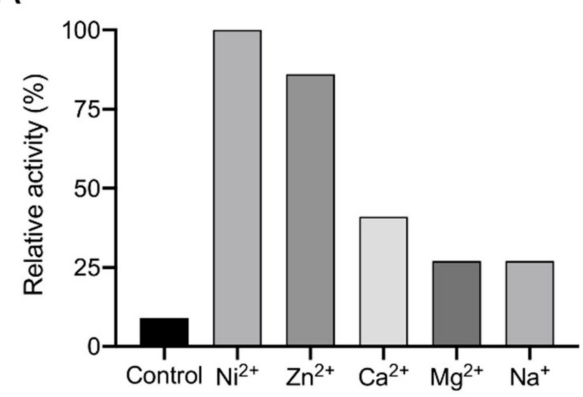

B

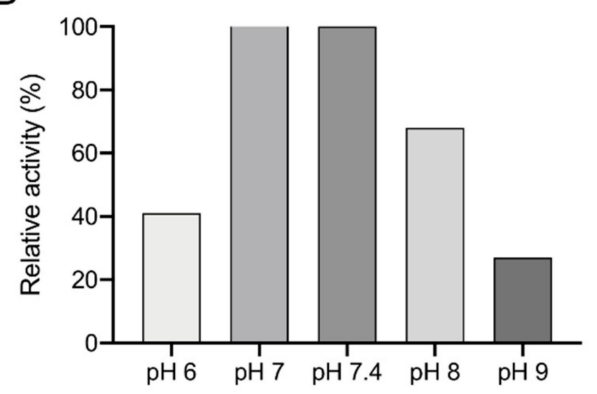

Figure 5. Influence of different metal ions and $\mathrm{pH}$ on the activity of recEhADH3B ${ }^{\mathrm{b}}$. (A) After removal of possible metal ions by EDTA $(10 \mathrm{mM})$, the purified recEhADH3B ${ }^{\mathrm{b}}$ was dialysed against an EDTA-free buffer and incubated for $1 \mathrm{~h}$ at $4{ }^{\circ} \mathrm{C}$ with different metal ions $(1 \mathrm{mM})$. Activity was measured using acetaldehyde $(20 \mathrm{mM})$ as substrate as well as NADPH $(0.7 \mathrm{mM})$. As control EDTA-treated and dialysed recEhADH3B ${ }^{\mathrm{b}}$ was used. Assays were performed in duplicate. Shown is the relative activity, where the activity of recEhADH3B ${ }^{\mathrm{b}}$ in the presence of $\mathrm{Ni}^{2+}$ was set as $100 \%$. (B) Dialyzed recEhADH3B ${ }^{\mathrm{b}}$ incubated with $\mathrm{Ni}^{2+}$ was used to determine the influence of the $\mathrm{pH}$ on acetaldehyde dehydrogenase activity. Shown is the relative activity, where the activity of recEhADH3B ${ }^{\mathrm{b}}$ in the presence of $\mathrm{Ni}^{2+}$ was set as $100 \%$.

\subsection{Localization of EhADH3B ${ }^{b}$}

The localization of EhADH3B ${ }^{\mathrm{b}}$ was analyzed in non-pathogenic $\mathrm{B} 8^{\mathrm{np}}$ using specific polyclonal mouse antibodies against rec EhADH3B ${ }^{\mathrm{b}}$ and by $A 1^{\text {np }}$ transfectants expressing EhADH3B ${ }^{\mathrm{b}}$ fused to a c-Myc tag. Using immunofluorescence microscopy, both approaches showed a localization of 
EhADH3B ${ }^{b}$ in the cytoplasm of all investigated amoebae. For only 3 of 90 analyzed B8 $8^{\text {np }}$ transfectants and 4 of 100 analyzed $A 1^{\text {np }}$ transfectants a surface localization in defined spots could be observed. No difference in localization was observed between the two non-pathogenic clones $A 1^{\text {np }}$ and $B 8^{\text {np }}$ (Figure 6). This localization pattern was also confirmed by confocal microscopy (Figure 7).

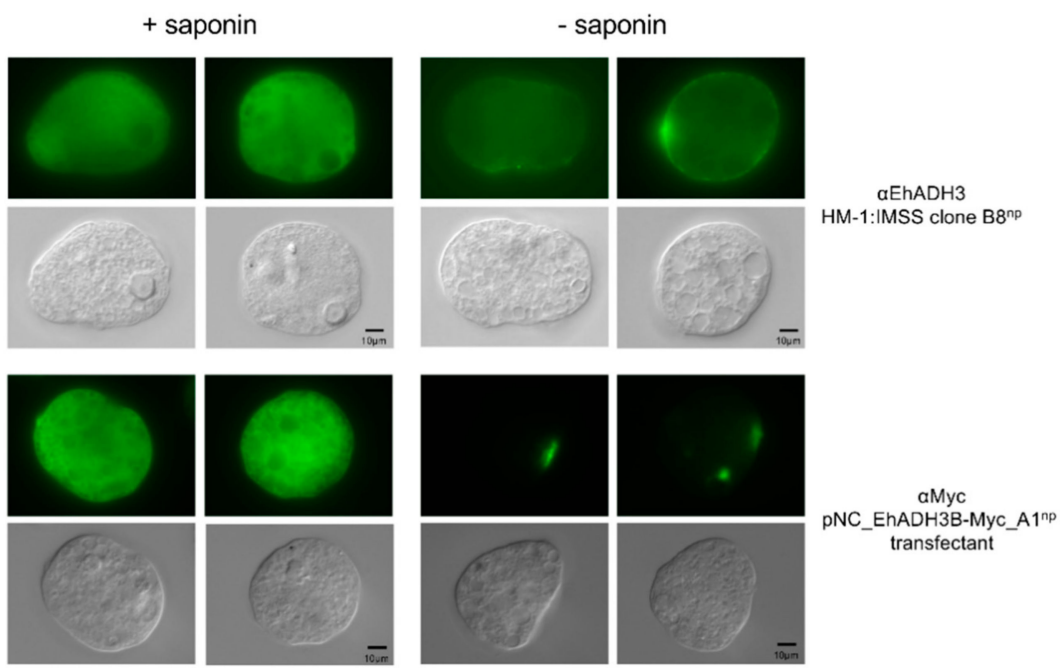

Figure 6. Localization of EhADH3B ${ }^{\mathrm{b}}$ in clone $\mathrm{B}^{\mathrm{np}}$ using polyclonal EhADH3B $\mathrm{B}^{\mathrm{b}}$ antibodies in and $\mathrm{A} 1^{\mathrm{np}}$ transfectants expressing $\mathrm{EhADH} 3 \mathrm{~B}^{\mathrm{b}}$ as c-myc fusion protein using anti c-myc for detection. Trophozoites were fixed with paraformaldehyde and treated with (+) or without (-) saponin. Afterwards, the trophozoites were incubated with specific antiserum (diluted 1:200 in NaPBS \pm saponin), followed by Alexa Fluor ${ }^{\circledR} 488$ goat anti-mouse secondary antibody. Localization was assessed by fluorescence microscopy (Leica, DM BR, Wetzlar, Germany).

A

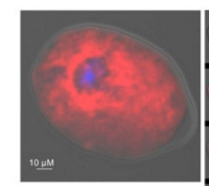

B

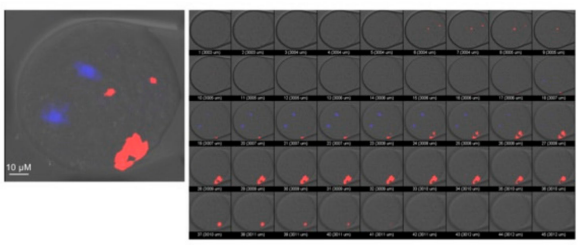

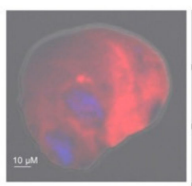

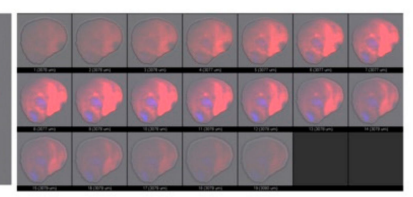

aEhADH3

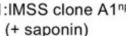

Figure 7. Localization of EhADH3B ${ }^{\mathrm{b}}$ in clone $\mathrm{A} 1^{\mathrm{np}}$ using polyclonal EhADH3B $\mathrm{B}^{\mathrm{b}}$ antibodies confocal microscope (Olympus IX81 microscope with the FluoView Version 1.7b software; Olympus, Hamburg, Germany). Amoebae were fixed with paraformaldehyde and treated with: (A) (+) or (B) without (-) saponin. The trophozoites were incubated with anti-EhEADH3B (diluted 1:200 in NaPBS \pm saponin), followed by Alexa Fluor ${ }^{\circledR} 488$ goat anti-mouse secondary antibody. Hoechst staining was used to visualize nuclei.

\section{Discussion}

In the genome of E. histolytica (AmoebaDB, release 48 beta, 27 August 2020) 13 genes coding for ADHs have been identified so far, which can be assigned to three families (EhADH1-3). Only one of these EhADH encoding genes, namely ehadh $3 b$ could be identified as being differentially expressed in a comparative transcriptome analysis between pathogenic and non-pathogenic amoebae. ehadh $3 b$ is one of only six genes that had been identified as being differentially expressed in two non-pathogenic 
E. histolytica clones (A1 $\left.{ }^{\mathrm{np}}, \mathrm{B} 8^{\mathrm{np}}\right)$ compared to one pathogenic clone $\left(\mathrm{B} 2^{\mathrm{p}}\right)$. Therefore ehadh $3 b$ shows an approximately 3-fold higher expression in the non-pathogenic isolates. Overexpression of ehadh $3 b^{b}$ significantly reduces the ability of $\mathrm{B}^{\mathrm{P}}$ amoebae to form amoebic liver abscesses [20]. The reason for this is so far unknown. To characterize the ehadh $3 b$ encoding enzyme in more detail, the phenotype of $e h a d h 3 b^{b}$ overexpressing and silencing transfectants as well as the enzymatic activity of the EhADH3B ${ }^{b}$ was analyzed in this study.

Ehadh3b occurs as a duplicate (EHI_088020 $\left(\right.$ ehadh3b $\left.b^{a}\right)$, EHI_160670 (ehadh3b $\left.b^{b}\right)$ ) in the genome of the E. histolytica isolate HM-1:IMSS. However, ehadh $3 b^{a}$ has a single nucleotide polymorphism which leads to a stop codon at position 496 of the nucleotide sequence. This mutation is found in all investigated axenically cultivated E. histolytica isolates. Interestingly, with one exception, this mutation is not detectable in amoebae isolated directly from stool samples of patients infected with E. histolytica. Whether the mutation is induced by the in vitro culture and whether it has an influence on the course of the disease is currently unknown.

BlastP analyses showed the highest homology ( $47 \%$ amino acid sequence identity) of EhADH3B ${ }^{\mathrm{b}}$ to iron-containing ADHs from anaerobic Gram-negative bacteria, such as Butyricimonas virosa, and Millionella massiliensis, which can be found in the gut microbiota. It can therefore be assumed that the EhADH3B coding genes was acquired via lateral gene transfer. This was also assumed for EhADH3A, which was shown also to have a common ancestor with gram-negative eubacteria [17]. Ehadh1 and ehadh 2 were probably also acquired by lateral gene transfer. In these cases, the genes of E. histolytica and Gram-positive eubacteria have a common ancestor [16].

As mentioned above, overexpression of ehadh $3 b^{b}$ in pathogenic B2 ${ }^{\mathrm{P}}$ amoebae significantly decreased the ability to form amoebic liver abscesses, whereas silencing had no influence on liver abscess formation of non-pathogenic B8 ${ }^{\text {np }}$ amoebae [20,21]. To explain this phenomenon, different phenotypes of the transfectants were analyzed, including hemolytic activity, cysteine peptidase activity, erythrophagocytosis, size, growth and motility. In no case differences between the overexpressing transfectants and the corresponding control were identified. Only for the silencing transfectants a significantly decreased cysteine peptidase activity and a significantly increased motility were detected. For a possible further phenotypic characterization, it should be noted that both overexpression and silencing have an effect on the expression of other genes. In particular, the silencing of the ehadh $3 b^{b}$ expression, in contrast to overexpression, also has an impact on other members of the ehadh 3 gene family. A similar phenomenon has already been described for the cysteine peptidase gene family of E. histolytica [21].

Using specific antibodies and transfectants expressing EhADH3B ${ }^{\mathrm{b}}$ as a c-Myc fusion protein, the enzyme was detected in the cytoplasm of all investigated amoebae. However, one of about 30 amoebae examined also showed a surface localization in distinct spots. This is consistent with studies investigating the surface proteome of E. histolytica. Besides EhADH3B ${ }^{\mathrm{b}}$, EhADH2 (EHI_150490), EhADH3A, EhADH3C and EHI_166490 were detected in the surface proteome [19]. The surface localization of EhADH3A was confirmed by staining the surface of live amoebae using an EhADH3A specific antibody [15]. However, the detection of the bifunctional EhADH2 in the membrane fraction might be due to co-sedimentation during membrane purification. The EhADH2 is a protein of 96 $\mathrm{kDa}$ which is composed of rod-like helical particles of $50-145 \mathrm{~nm}$ in size, which can be detected in a $160,000 \times g$ pellet after centrifugation $[5,26]$.

To characterize the enzymatic activity in detail, EhADH3B ${ }^{\mathrm{b}}$ was recombinantly expressed in E. coli and purified. It was shown that recEhADH3B ${ }^{b}$ has a NADPH-dependent reductive activity mainly against acetaldehyde. A lower activity against formaldehyde was also be detected. Many properties of EhADH3B ${ }^{\mathrm{b}}$ correspond to the YqhD group of bacterial ADH3s, although there is little homology at the sequence level (e.g., 37\% amino acid sequence identify to PaYqhD of Pectobacterium atrosepticum) [29,30]. YqhD group proteins and EhADH3B $\mathrm{B}^{\mathrm{b}}$ are active as dimers [29]. Besides the conserved region that binds the cofactor (GGGSxxD-motif), YqhD also has a second GGGS-motif at the N-terminus, which is conserved in all bacterial YqhD-like enzymes. Both domains are also found in all four members of the EhADH3 family. 
EhADH3B ${ }^{b}$ as well as YqhD are NADPH-dependent enzymes. The NAD-binding ADH3 of the DhaT group of Zymomonas mobilis ( $\mathrm{ZmADH}$ ) and E. coli (FucO) has a conserved aspartic acid (position 39), which is not present in the YqhD-like enzymes nor in the EhADH3 family. Instead of the NAD-binding ADH3 of the DhaT group we find a N-terminal tyrosin of the second GGGS-motif (YGGGS) [30]. Comparable to the PaYqhD, the highest enzymatic activity for recEhADH3B ${ }^{\mathrm{b}}$ had been observed at $\mathrm{pH} 7.0$ [30]. Interestingly, YqhD and $\mathrm{EhADH}_{3} \mathrm{~B}^{\mathrm{b}}$ are not able to oxidize alcoholic compounds. However, there are also some differences between the EhADH3B ${ }^{\mathrm{b}}$ and the PaYqhD. This is particularly true for the metal cofactor. The activity of recEhADH3B ${ }^{b}$ can be completely inhibited by the addition of EDTA and by adding $\mathrm{Ni}^{2+}$ or $\mathrm{Zn}^{2+}$, it can be completely restored. For PaYqhD a reactivation takes place by the addition of $\mathrm{Co}^{2+}$, while $\mathrm{Zn}^{2+}$ and $\mathrm{Fe}^{2+}$ did not reactivate the enzyme [30]. In contrast $\mathrm{ZmADH} 2$ is an $\mathrm{Fe}^{2+}$-dependent enzyme. The exchange of $\mathrm{Fe}^{2+}$ with $\mathrm{Cu}^{2+}, \mathrm{Mn}^{2+}, \mathrm{Ni}^{2+}$, or $\mathrm{Zn}^{2+}$ resulted in loss of activity [31,32]. The metal ion in the active site of E. coli YqhD is $\mathrm{Zn}^{2+}$ [33]. Interestingly, the NAD-dependent DhaT of Oenococcus oeni is active in the presence of $\mathrm{Ni}^{2+}$, as the EhADH3B ${ }^{b}$ is. However, in contrast to EhADH3B ${ }^{\mathrm{b}}, \mathrm{DhaT}$ is inhibited in the presence of $\mathrm{Zn}^{2+}$ [28]. The E. histolytica EhADH1 contains $\mathrm{Zn}^{2+}$ in the active center, while the bifunctional EhADH2 (ADH and aldehyde dehydrogenase (ALDH)) is $\mathrm{Fe}^{2+}$ dependent $[7,34,35]$.

As mentioned above, recEhADH3B ${ }^{b}$ acts as NADP $(\mathrm{H})$-dependent aldehyde reductase and has no alcohol oxidation activity. Interestingly, EhADH3A and EhADH3B ${ }^{\mathrm{b}}$ differ in their enzymatic properties despite having a sequence identity of $70 \%$. While both are NADP $(\mathrm{H})$ dependent, EhADH3A oxidizes short-chain unbranched alcohols such as ethanol at a $\mathrm{pH}$ of 9.0, while EhADH3B ${ }^{\mathrm{b}}$ only catalyzes aldehyde reduction at a $\mathrm{pH}$ of 7.0 [15]. Just like EhADH3B ${ }^{\mathrm{b}}, \mathrm{PaYqhD}$ acts as NADP(H)-dependent aldehyde reductase and has no alcohol oxidation activity. While EhADH3B ${ }^{\mathrm{b}}$ has the strongest activity against ethanal (acetaldehyde) and to a lesser extent against methanal (formaldehyde), PaYqhD has the strongest activity against aldehydes with short carbon chains such as butanal, pentanal hexanal, hepanal and octanal [30]. The YqhD of E. coli also functions as aldehyde reductase with a broad range of short-chain aldehydes [33,36]. However, YqhD did not show dehydrogenase activity on alcoholic substrates such as methanol, ethanol, propanol, butanol, and isopropanol [30,36]. While it is assumed that YqhD enzymes are mainly responsible for the detoxification of aldehydes that play a role in lipid peroxidation, it can be assumed that EhADH3B ${ }^{\mathrm{b}}$ plays a role in the reduction of free acetaldehydes released from the ADH2-bound thiohemiacetal by hydrolysis, which has also been postulated by Reeves [2,29,33,36].

It is also interesting that $\mathrm{EhADH}_{3} \mathrm{~B}^{\mathrm{b}}$ can detoxify formaldehyde. Formaldehyde can be produced in the intestines in various ways. The human ADH1 can oxidize methanol and thereby produce formaldehyde. The conversion of methanol to formaldehyde can also be achieved by catalase and cytochrome p450 (CYP2E1) mediated oxidation (for review [37]). Furthermore, human microbiota produces methanol, which can be oxidized to formaldehydes, by methanol dehydrogenases and ADHs. In most cases formaldehyde is converted by the bacteria to formic acid and carbon dioxide. In addition, humans ingest both acetaldehydes and formaldehydes through the food. The average intake for acetaldehydes is $40 \mu \mathrm{g} / \mathrm{kg}$ and for formaldehydes $1.5-14 \mathrm{mg} /$ day [38,39], for review [37].

Finally, it cannot be clarified why EhADH3B ${ }^{\mathrm{b}}$ is more strongly expressed in non-pathogenic amoebae than in pathogenic ones and why overexpression reduces the virulence of E. histolytica. However, EhADH3B ${ }^{\mathrm{b}}$ seems to be involved in the detoxification of aldehydes, in particular acetaldehyde and formaldehyde, similar to what has been described for bacteria ADH3 enzymes before.

Supplementary Materials: The following are available online at http://www.mdpi.com/2076-2607/8/10/1608/s1, Table S1: Oligonucleotides for gene amplification and for analysis of gene expression using qPCR, Table S2: NGS analysis of clone $\mathrm{B}^{\mathrm{p}}$ transfected with either plasmid $\mathrm{pNC}$ (control) or $\mathrm{pNC}$-ehadh $3 b^{b}$ resulting in overexpression of $e h a d h 3 b^{b}$. 
Author Contributions: Conceptualization, I.B., M.M.; methodology, C.K., M.M., C.L., S.N., T.W., T.H., T.M., D.L., J.M., H.F., S.R., M.R., H.L.; software, I.B.; validation, C.K., C.L., S.N; formal analysis, S.N., C.L., I.B.; investigation, C.K., M.M., C.L., S.N., T.W., T.H., T.M., D.L., J.M., H.F., M.R; data curation, I.B.; writing-original draft preparation, C.K., I.B.; writing-review and editing, I.B., H.L., H.F., C.L., C.K., T.R., M.R., N.G.M.; visualization, I.B.; supervision, I.B.; funding acquisition, C.K., M.M, I.B. All authors contributed to the preparation of the final version of the manuscript. All authors have read and agreed to the published version of the manuscript.

Funding: The research was funded by the Deutsche Forschungsgemeinschaft (BR1744/17-1) and the Jürgen Manchot Stiftung.

Acknowledgments: We like to thank Stephan Lorenzen for bioinformatic data analyses.

Conflicts of Interest: The authors declare no conflict of interest.

\section{References}

1. GBD 2013 Mortality and Causes of Death Collaborators. Global, regional, and national age-sex specific all-cause and cause-specific mortality for 240 causes of death, 1990-2013: A systematic analysis for the Global Burden of Disease Study 2013. Lancet 2015, 385, 117-171. [CrossRef]

2. Reeves, R.E. Metabolism of Entamoeba histolytica Schaudinn, 1903. Adv. Parasitol. 1984, 23, $105-142$. [PubMed]

3. Lo, H.S.; Reeves, R.E. Pyruvate-to-ethanol pathway in Entamoeba histolytica. Biochem. J. 1978, 171, $225-230$. [CrossRef] [PubMed]

4. Muller, M. Energy metabolism of protozoa without mitochondria. Annu. Rev. Microbiol. 1988, 42, 465-488. [CrossRef]

5. Bruchhaus, I.; Tannich, E. Purification and molecular characterization of the NAD(+)-dependent acetaldehyde/alcohol dehydrogenase from Entamoeba histolytica. Biochem. J. 1994, 303, 743-748. [CrossRef]

6. Chen, M.; Li, E.; Stanley, S.L., Jr. Structural analysis of the acetaldehyde dehydrogenase activity of Entamoeba histolytica alcohol dehydrogenase 2 (EhADH2), a member of the ADHE enzyme family. Mol. Biochem. Parasitol. 2004, 137, 201-205. [CrossRef]

7. Espinosa, A.; Yan, L.; Zhang, Z.; Foster, L.; Clark, D.; Li, E.; Stanley, S.L., Jr. The bifunctional Entamoeba histolytica alcohol dehydrogenase 2 (EhADH2) protein is necessary for amebic growth and survival and requires an intact C-terminal domain for both alcohol dahydrogenase and acetaldehyde dehydrogenase activity. J. Biol. Chem. 2001, 276, 20136-20143. [CrossRef]

8. Reyes-Lopez, M.; Bermudez-Cruz, R.M.; Avila, E.E.; de la Garza, M. Acetaldehyde/alcohol dehydrogenase-2 (EhADH2) and clathrin are involved in internalization of human transferrin by Entamoeba histolytica. Microbiology 2011, 157, 209-219. [CrossRef]

9. Reeves, R.E.; Montalvo, F.E.; Lushbaugh, T.S. Nicotinamide-adenine dinucleotide phosphate-dependent alcohol dehydrogenase: The enzyme from Entamoeba histolytica and some inhibitors. Int. J. Biochem. 1971, 2, 55-64. [CrossRef]

10. Lo, H.S.; Chang, C.J. Purification and properties of NADP-linked, alcohol dehydrogenase from Entamoeba histolytica. J. Parasitol. 1982, 68, 372-377. [CrossRef]

11. Kumar, A.; Shen, P.S.; Descoteaux, S.; Pohl, J.; Bailey, G.; Samuelson, J. Cloning and expression of an NADP(+)-dependent alcohol dehydrogenase gene of Entamoeba histolytica. Proc. Natl. Acad. Sci. USA 1992, 89, 10188-10192. [CrossRef] [PubMed]

12. Samuelson, J.; Zhang, W.W.; Kumar, A.; Descoteaux, S.; Shen, P.S.; Bailey, G. Primary structures of alcohol and aldehyde dehydrogenase genes of Entamoeba histolytica. Arch. Med. Res. 1992, 23, 31-33. [PubMed]

13. Rodriguez, M.A.; Baez-Camargo, M.; Delgadillo, D.M.; Orozco, E. Cloning and expression of an Entamoeba histolytica NAPD+(-)dependent alcohol dehydrogenase gene. Biochim. Biophys. Acta 1996, 1306, 23-26. [CrossRef]

14. Kimura, A.; Hara, Y.; Kimoto, T.; Okuno, Y.; Minekawa, Y.; Nakabayashi, T. Cloning and expression of a putative alcohol dehydrogenase gene of Entamoeba histolytica and its application to immunological examination. Clin. Diagn. Lab. Immunol. 1996, 3, 270-274. [CrossRef]

15. Davis, P.H.; Chen, M.; Zhang, X.; Clark, C.G.; Townsend, R.R.; Stanley, S.L., Jr. Proteomic comparison of Entamoeba histolytica and Entamoeba dispar and the role of E. histolytica alcohol dehydrogenase 3 in virulence. PLoS Negl. Trop. Dis. 2009, 3, e415. [CrossRef] 
16. Field, J.; Rosenthal, B.; Samuelson, J. Early lateral transfer of genes encoding malic enzyme, acetyl-CoA synthetase and alcohol dehydrogenases from anaerobic prokaryotes to Entamoeba histolytica. Mol. Microbiol. 2000, 38, 446-455. [CrossRef] [PubMed]

17. Nixon, J.E.; Wang, A.; Field, J.; Morrison, H.G.; McArthur, A.G.; Sogin, M.L.; Loftus, B.J.; Samuelson, J. Evidence for lateral transfer of genes encoding ferredoxins, nitroreductases, NADH oxidase, and alcohol dehydrogenase 3 from anaerobic prokaryotes to Giardia lamblia and Entamoeba histolytica. Eukaryot. Cell 2002, 1, 181-190. [CrossRef] [PubMed]

18. Flores, B.M.; Stanley, S.L., Jr.; Yong, T.S.; Ali, M.; Yang, W.; Diedrich, D.L.; Torian, B.E. Surface localization, regulation, and biologic properties of the $96-\mathrm{kDa}$ alcohol/aldehyde dehydrogenase (EhADH2) of pathogenic Entamoeba histolytica. J. Infect. Dis. 1996, 173, 226-231. [CrossRef]

19. Biller, L.; Matthiesen, J.; Kuhne, V.; Lotter, H.; Handal, G.; Nozaki, T.; Saito-Nakano, Y.; Schumann, M.; Roeder, T.; Tannich, E.; et al. The Cell Surface Proteome of Entamoeba histolytica. Mol. Cell. Proteom. 2014, 13, 132-144. [CrossRef]

20. Meyer, M.; Fehling, H.; Matthiesen, J.; Lorenzen, S.; Schuldt, K.; Bernin, H.; Zaruba, M.; Lender, C.; Ernst, T.; Ittrich, H.; et al. Overexpression of differentially expressed genes identified in non-pathogenic and pathogenic Entamoeba histolytica clones allow identification of new pathogenicity factors involved in amoebic liver abscess formation. PLoS Pathog. 2016, 12, e1005853. [CrossRef]

21. Matthiesen, J.; Lender, C.; Haferkorn, A.; Fehling, H.; Meyer, M.; Matthies, T.; Tannich, E.; Roeder, T.; Lotter, H.; Bruchhaus, I. Trigger-induced RNAi gene silencing to identify pathogenicity factors of Entamoeba histolytica. FASEB J. 2019, 33, 1658-1668. [CrossRef]

22. Diamond, L.S.; Harlow, D.R.; Cunnick, C.C. A new medium for axenic cultivation of Entamoeba histolytica and other Entamoeba. Trans. R. Soc. Trop. Med. Hyg. 1978, 72, 431-432. [CrossRef]

23. Biller, L.; Schmidt, H.; Krause, E.; Gelhaus, C.; Matthiesen, J.; Handal, G.; Lotter, H.; Janssen, O.; Tannich, E.; Bruchhaus, I. Comparison of two genetically related Entamoeba histolytica cell lines derived from the same isolate with different pathogenic properties. Proteomics 2009, 9, 4107-4120. [CrossRef]

24. Leippe, M.; Sievertsen, H.J.; Tannich, E.; Horstmann, R.D. Spontaneous release of cysteine proteinases but not of pore-forming peptides by viable Entamoeba histolytica. Parasitology 1995, 111, 569-574. [CrossRef]

25. Clark, C.G.; Alsmark, U.C.; Tazreiter, M.; Saito-Nakano, Y.; Ali, V.; Marion, S.; Weber, C.; Mukherjee, C.; Bruchhaus, I.; Tannich, E.; et al. Structure and content of the Entamoeba histolytica genome. Adv. Parasitol. 2007, 65, 51-190.

26. Avila, E.E.; Martinez-Alcaraz, E.R.; Barbosa-Sabanero, G.; Rivera-Baron, E.I.; Arias-Negrete, S.; Zazueta-Sandoval, R. Subcellular localization of the NAD+-dependent alcohol dehydrogenase in Entamoeba histolytica trophozoites. J. Parasitol. 2002, 88, 217-222. [CrossRef] [PubMed]

27. Yang, W.; Li, E.; Kairong, T.; Stanley Jr, S.L. Entamoeba histolytica has an alcohol dehydrogenase homologous to the multifunctional adhE gene product of Escherichia coli, Mol. Biochem. Parasitol. 1994, 64, 253-260. [CrossRef]

28. Elleuche, S.; Fodor, K.; Klippel, B.; von der Heyde, A.; Wilmanns, M.; Antranikian, G. Structural and biochemical characterisation of a $\mathrm{NAD}(+)$-dependent alcohol dehydrogenase from Oenococcus oeni as a new model molecule for industrial biotechnology applications. Appl. Microbiol. Biotechnol. 2013, 97, 8963-8975. [CrossRef] [PubMed]

29. Jarboe, L.R. YqhD: A broad-substrate range aldehyde reductase with various applications in production of biorenewable fuels and chemicals. Appl. Microbiol. Biotechnol. 2011, 89, 249-257. [CrossRef] [PubMed]

30. Elleuche, S.; Fodor, K.; von der Heyde, A.; Klippel, B.; Wilmanns, M.; Antranikian, G. Group III alcohol dehydrogenase from Pectobacterium atrosepticum: Insights into enzymatic activity and organization of the metal ion-containing region. Appl. Microbiol. Biotechnol. 2014, 98, 4041-4051. [CrossRef] [PubMed]

31. Moon, J.H.; Lee, H.J.; Park, S.Y.; Song, J.M.; Park, M.Y.; Park, H.M.; Sun, J.; Park, J.H.; Kim, B.Y.; Kim, J.S. Structures of iron-dependent alcohol dehydrogenase 2 from Zymomonas mobilis ZM4 with and without NAD+ cofactor. J. Mol. Biol. 2011, 407, 413-424. [CrossRef] [PubMed]

32. Reid, M.F.; Fewson, C.A. Molecular characterization of microbial alcohol dehydrogenases. Crit. Rev. Microbiol. 1994, 20, 13-56. [CrossRef]

33. Sulzenbacher, G.; Alvarez, K.; Van Den Heuvel, R.H.; Versluis, C.; Spinelli, S.; Campanacci, V.; Valencia, C.; Cambillau, C.; Eklund, H.; Tegoni, M. Crystal structure of E.coli alcohol dehydrogenase YqhD: Evidence of a covalently modified NADP coenzyme. J. Mol. Biol. 2004, 342, 489-502. [CrossRef] [PubMed] 
34. Cabrera, N.; Rangel, P.; Hernandez-Munoz, R.; Perez-Montfort, R. Purification of alcohol dehydrogenase from Entamoeba histolytica and Saccharomyces cerevisiae using zinc-affinity chromatography. Protein Expr. Purif. 1997, 10, 340-344. [CrossRef] [PubMed]

35. Espinosa, A.; Perdrizet, G.; Paz, Y.M.C.G.; Lanfranchi, R.; Phay, M. Effects of iron depletion on Entamoeba histolytica alcohol dehydrogenase $2(\mathrm{EhADH} 2)$ and trophozoite growth: Implications for antiamoebic therapy. J. Antimicrob. Chemother. 2009, 63, 675-678. [CrossRef] [PubMed]

36. Perez, J.M.; Arenas, F.A.; Pradenas, G.A.; Sandoval, J.M.; Vasquez, C.C. Escherichia coli YqhD exhibits aldehyde reductase activity and protects from the harmful effect of lipid peroxidation-derived aldehydes. $J$. Biol. Chem. 2008, 283, 7346-7353. [CrossRef]

37. Dorokhov, Y.L.; Shindyapina, A.V.; Sheshukova, E.V.; Komarova, T.V. Metabolic methanol: Molecular pathways and physiological roles. Physiol. Rev. 2015, 95, 603-644. [CrossRef]

38. Tsuchiya, K.; Hayashi, Y.; Onodera, M.; Hasegawa, T. Toxicity of formaldehyde in experimental animals-concentrations of the chemical in the elution from dishes of formaldehyde resin in some vegetables. Keio J. Med. 1975, 24, 19-37. [CrossRef]

39. Dhareshwar, S.S.; Stella, V.J. Your prodrug releases formaldehyde: Should you be concerned? No! J. Pharm. Sci. 2008, 97, 4184-4193. [CrossRef]

Publisher's Note: MDPI stays neutral with regard to jurisdictional claims in published maps and institutional affiliations.

(C) 2020 by the authors. Licensee MDPI, Basel, Switzerland. This article is an open access article distributed under the terms and conditions of the Creative Commons Attribution (CC BY) license (http://creativecommons.org/licenses/by/4.0/). 